\title{
IRSp53 Deletion in Glutamatergic and GABAergic Neurons and in Male and Female Mice Leads to Distinct Electrophysiological and Behavioral Phenotypes
}

OPEN ACCESS

Edited by:

Lei Shi,

Jinan University, China

Reviewed by:

Bin Jiang,

Sun Yat-sen University, China Jean-Pierre Mothet,

UMR9188 Laboratoire Aimé Cotton $(L A C)$, France

${ }^{*}$ Correspondence: Eunjoon Kim kime@kaist.ac.kr

tThese authors have contributed equally to this work

Received: 30 November 2019 Accepted: 27 January 2020 Published: 11 February 2020

Citation: Kim Y, Noh YW, Kim K, Yang E, Kim H and Kim E (2020) IRSp53 Deletion in Glutamatergic and GABAergic Neurons and in Male and Female Mice Leads to Distinct Electrophysiological and Behavioral Phenotypes.

Front. Cell. Neurosci. 14:23. doi: 10.3389/fncel.2020.00023

\author{
Yangsik Kim ${ }^{1 \dagger}$, Young Woo $\mathrm{Noh}^{2 \dagger}$, Kyungdeok $\mathrm{Kim}^{2}$, Esther Yang ${ }^{3}$, Hyun $\mathrm{Kim}^{3}$ \\ and Eunjoon $\mathrm{Kim}^{2,4 *}$
}

${ }^{1}$ Graduate School of Medical Science and Engineering, Korea Advanced Institute of Science and Technology (KAIST),

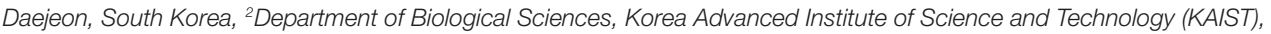
Daejeon, South Korea, ${ }^{3}$ Department of Anatomy, College of Medicine, Korea University, Seoul, South Korea, ${ }^{4}$ Center for Synaptic Brain Dysfunctions, Institute for Basic Science (IBS), Daejeon, South Korea

IRSp53 (also known as BAIAP2) is an abundant excitatory postsynaptic scaffolding protein implicated in autism spectrum disorders (ASD), schizophrenia, and attentiondeficit/hyperactivity disorder (ADHD). IRSp53 is expressed in different cell types across different brain regions, although it remains unclear how IRSp53 deletion in different cell types affects brain functions and behaviors in mice. Here, we deleted IRSp53 in excitatory and inhibitory neurons in mice and compared resulting phenotypes in males and females. IRSp53 deletion in excitatory neurons driven by Emx1 leads to strong social deficits and hyperactivity without affecting anxiety-like behavior, whereas IRSp53 deletion in inhibitory neurons driven by Viaat has minimal impacts on these behaviors in male mice. In female mice, excitatory neuronal IRSp53 deletion induces hyperactivity but moderate social deficits. Excitatory neuronal IRSp53 deletion in male mice induces an increased ratio of evoked excitatory and inhibitory synaptic transmission ( $E / /$ ratio) in layer $\mathrm{V}$ pyramidal neurons in the prelimbic region of the medial prefrontal cortex (mPFC), whereas the same mutation does not alter the $\mathrm{E} / \mathrm{I}$ ratio in female neurons. These results suggest that IRSp53 deletion in excitatory and inhibitory neurons and in male and female mice has distinct impacts on behaviors and synaptic transmission.

Keywords: autism, synapse, IRSp53, mPFC, social interaction, hyperactivity

\section{INTRODUCTION}

IRSp53 (encoded by Baiap2) is a multi-domain scaffolding or adaptor protein that is abundantly present in the postsynaptic density of excitatory synapses (Sheng and Kim, 2011; Kang et al., 2016). IRSp53 directly interacts with PSD-95 and Shank, excitatory postsynaptic scaffolding proteins known to regulate synapse assembly and function and implicated in various brain disorders, including autism spectrum disorders (ASD; Sheng and Sala, 2001; Sheng and Hoogenraad, 2007; Jiang and Ehlers, 2013; Sala et al., 2015; Monteiro and Feng, 2017). 
Functionally, IRSp53 regulates dendritic spines and synaptic function through its ability to coordinate Rac and Cdc42 small GTPase-dependent modulation of actin filaments (Kang et al., 2016), the main cytoskeleton of dendritic spines (Sala and Segal, 2014).

Global deletion of IRSp53 in mice decreases dendritic spine density in the cortex and induces abnormal behaviors, including social-interaction deficits, hyperactivity, and cognitive impairments (Sawallisch et al., 2009; Chung et al., 2015), in line with the reported implication of IRSp53/BAIAP2 in ASD (Celestino-Soper et al., 2011; Levy et al., 2011; Toma et al., 2011), schizophrenia (Fromer et al., 2014; Purcell et al., 2014), and attention-deficit/hyperactivity disorder (ADHD; Ribasés et al., 2009; Liu et al., 2013). In addition, global IRSp53 deletion in mice abnormally increases the function of $\mathrm{N}$-methyl-D-aspartate receptors (NMDARs) in the hippocampus, and the NMDAR antagonist memantine improves social deficits in IRSp53-mutant mice (Kim et al., 2009; Chung et al., 2015; Bobsin and Kreienkamp, 2016), supporting the growing importance of NMDAR dysfunction in ASD (Lee et al., 2015). A previous study has shown that IRSp53 is expressed in various cell types, including excitatory neurons in the neocortex and GABAergic neurons in the striatum and cerebellum (Burette et al., 2014). However, the impacts of cell type-specific IRSp53 expression on brain functions and behaviors, including social interaction, remain essentially unknown.

Here, we restricted Irsp53 knockout (KO) in dorsal telencephalic glutamatergic neurons using Emx1-Cre mice and GABAergic neurons using Viaat-Cre mice, and found that glutamatergic Irsp53 KO led to social deficits and hyperactivity associated with increased ratio of evoked excitatory and inhibitory synaptic transmission (E/I ratio) in the medial prefrontal cortex (mPFC) of male mice. In female mice, glutamatergic Irsp53 $\mathrm{KO}$ led to moderate social deficits that are associated with an unaltered cortical E/I ratio.

\section{MATERIALS AND METHODS}

\section{Animals}

Mice were bred and maintained according to the Requirements of Animal Research at KAIST. All procedures were approved and followed by the Committee of Animal Research at KAIST (KA201). We used male mice for behavioral, electrophysiological, and other (biochemical, FISH, and tdTomato expression in Emx1- and Viaat-Cre mice) experiments; female mice were also used for behavioral tests [three-chamber and open-field test (OFT)] and electrophysiology.

Mice were fed ad libitum, and 2-4 mice were housed together in a cage under a 12-h light-dark cycle. There were no differences in the body weights of age-matched mouse groups. Mice were identified by polymerase chain reaction (PCR) genotyping using the following PCR primers: IRSp53 flox AGGAGGTGTTTCTGCTCTGG/AATAGCAGTCTGGGGTC TGG; Cre CGTACTGACGGTGGGAGAAT/TGCATGATCT CCGGTATTGA.

\section{Behavioral Assays}

All behavioral assays were performed using age-matched C57BL6/J mice (8-16 weeks) generated by Cre/+; Irsp $53^{\text {flox } /+} \times \operatorname{Irsp} 53^{\text {flox/flox }}$ mating. All behavioral assays were performed during light-off periods. The light condition for all behavioral assays was $\sim 120$ lux. There were at least 1 day-long rest periods between tests. The behavioral assays were performed in the order of the open field test, elevated plus-maze (EPM) test, and three-chamber social interaction test. Behavioral assays were recorded as video files (.avi format) and analyzed by Ethovision XT 10 (Noldus, The Netherlands).

\section{Three-Chamber Social Interaction Test}

The three-chambered social-interaction test was performed as described previously (Moy et al., 2004; Silverman et al., 2010). The apparatus had the following dimensions; W $60 \times \mathrm{H} 40 \times \mathrm{D}$ $20 \mathrm{~cm}$ for the whole apparatus, and W $20 \times \mathrm{H} 20 \times \mathrm{D}$ $20 \mathrm{~cm}$ for each chamber. The side chambers contained an aluminum grid with a curved face to confine the mouse/object. The assay consisted of three sessions. During the first 10-min session, a subject mouse was allowed to freely explore all three chambers for habituation. Then the mouse was confined briefly in the center chamber, while a novel object and a WT stranger mouse, stranger 1 , were placed in the side chambers behind the aluminum grid in a random manner to minimize the influences of side bias. The subject mouse was then allowed to freely explore all three chambers for $10 \mathrm{~min}$. Before the last session, the subject mouse was again gently guided to the center chamber while the object was replaced with another WT mouse, stranger 2. The subject mouse was again allowed to freely explore all three chambers for $10 \mathrm{~min}$.

In a modified three-chamber social interaction test performed for five consecutive days to measure social novelty in mice (Bariselli et al., 2018), we used the same apparatus and social interaction scheme. This test used an empty aluminum grid without an object, unlike the conventional three-chamber social interaction test. A subject mouse was exposed to the first stranger for the first 4 days to maximize habituation to the stranger, and the stranger was placed in alternate chambers to suppress the effect of side bias. One day 5 , the first stranger was replaced with the second stranger to measure social-novelty recognition.

All stranger mice were age-matched males and were habituated to the side chambers in advance during the previous day for $30 \mathrm{~min}$. The positions of the object and stranger mouse were alternated between tests to minimize the influences of side preference.

\section{Open-Field Test}

Mice were placed in the center region of an open-field box $(40 \times 40 \times 40 \mathrm{~cm})$. Open-field locomotor activities were measured for $60 \mathrm{~min}$.

\section{Elevated Plus-Maze Test}

An elevated-plus maze was made of gray acryl with four arms, each 30-cm long and 5-cm wide (Walf and Frye, 2007). The height of the maze was elevated $75 \mathrm{~cm}$ above the ground. The light condition of closed arms was $\sim 0$ lux. A test mouse was placed in the center of the maze at the junction of the four arms 
in the beginning and was allowed to freely explore the maze for $10 \mathrm{~min}$.

\section{Whole-Cell Recordings}

Coronal slices (mPFC) were prepared using a vibratome (VT1200S, Leica, Germany) in ice-cold dissection buffer (in mM: 212 sucrose, $25 \mathrm{NaHCO}_{3}, 5 \mathrm{KCl}, 1.25 \mathrm{NaH}_{2} \mathrm{PO}_{4}$, $10 \mathrm{D}$-glucose, 2 sodium pyruvate, 1.2 sodium ascorbate, 3.5 $\mathrm{MgCl}_{2}, 0.5 \mathrm{CaCl}_{2}$ bubbled with 95\% $\left.\mathrm{O} 2 / 5 \% \mathrm{CO}_{2}\right)$. The slices were recovered at $32{ }^{\circ} \mathrm{C}$ in normal artificial cerebrospinal fluid (ACSF; in mM: $125 \mathrm{NaCl}, 25 \mathrm{NaHCO}_{3}$, $2.5 \mathrm{KCl}, 1.25 \mathrm{NaH}_{2} \mathrm{PO}_{4}, 10$ D-glucose, $1.3 \mathrm{MgCl}_{2}, 2.5 \mathrm{CaCl}_{2}$ ) and thereafter maintain at room temperature. Cells were visualized using infrared differential interference contrast video microscopy (Olympus, BX50XI). Whole-cell current-clamp recordings were made by using a MultiClamp 700B amplifier (Molecular Devices).

For voltage-clamp recordings, recording pipettes (3-5 M $\Omega$ ) were filled with a solution containing (in mM) $120 \mathrm{CsMeSO}_{4}$, $15 \mathrm{CsCl}, 10$ TEA-Cl, $8 \mathrm{NaCl}, 10$ HEPES, 0.25 EGTA, 5 QX314, $4 \mathrm{MgATP}$, and 0.3 NaGTP, pH 7.25-7.35 (280-300 mOsm; Rothwell et al., 2014). Signals were filtered at $2 \mathrm{kHz}$ and digitized at $10 \mathrm{kHz}$. Miniature excitatory postsynaptic currents (mEPSCs) were recorded in the presence of AP5 $(50 \mu \mathrm{M})$ and tetrodotoxin $(1 \mu \mathrm{M})$ at the holding potential of $-70 \mathrm{mV}$. Miniature inhibitory postsynaptic currents (mIPSCs) were recorded at the holding potential of $0 \mathrm{mV}$, as described previously (Liang et al., 2015). For voltage-clamp recordings with electrical stimulation (NMDA/AMPA ratio, paired-pulse ratio, and excitatory/inhibitory ratio), a stimulus pipette was located $100 \mu \mathrm{m}$ toward the pia from the patched cell. Stimulus electrode was soaked in the abovementioned bath solution, and $1 / 15 \mathrm{~Hz}$ stimulation was used to obtain baseline responses (20/8/20 for NMDA/AMPA ratio, paired-pulse ratio, and excitatory/inhibitory ratio, respectively). Stimulus intensity was modified in different experiments (NMDA/AMPA ratio, $<10 \mathrm{pA}$ at $50 \mathrm{~ms}$ after stimulation; paired-pulse ratio, $60 \mathrm{pA}<$ EPSC $1<200 \mathrm{pA}$ ).

For current-clamp recordings, recording pipettes (3-5 M $\Omega$ ) were filled with a solution containing (in $\mathrm{mM}$ ) 120 Kgluconate, 20 HEPES, 0.4 EGTA, $2.8 \mathrm{NaCl}$, 5 TEA-Cl, $2.5 \mathrm{MgATP}$, and 0.25 NaGTP, pH 7.25-7.35 (280-300 mOsm). Picrotoxin $(100 \mu \mathrm{M})$ and NBQX $(10 \mu \mathrm{M})$ were present throughout the experiments to block inhibitory and excitatory synaptic transmissions, respectively. If the series resistance changed by more than $20 \%$, data were not included in the analysis. Membrane potentials were not corrected for junction potentials (estimated to be $10 \mathrm{mV}$ ). To obtain sustained firings, a series of current (1 s duration, $50 \mathrm{pA}$ steps for $\mathrm{mPFC}$ ) was injected. To measure action potential thresholds, a series of current steps $(2 \mathrm{~ms}$ duration at $2.5 \mathrm{~Hz}, 0-2,500 \mathrm{pA}$ range, $+10 \mathrm{pA}$ step increments) were injected into patched neurons until an action potential was generated. To measure the input resistance, hyperpolarizing current steps ( $1 \mathrm{~s}$ duration, 0 to $-100 \mathrm{pA}$, $-25 \mathrm{pA}$ step increments) were injected into patched neurons. All voltage measures were taken after neurons had reached a stable response (Chen et al., 2013).

\section{Immunoblotting and Immunofluorescence}

For immunoblotting experiments, a fresh brain was homogenized with ice-cold lysis buffer containing $320 \mathrm{mM}$ sucrose, $10 \mathrm{mM}$ HEPES $\mathrm{pH}$ 7.4, $5 \mathrm{mM}$ EDTA, and protease inhibitors. For immunofluorescence experiments, isoflurane-anesthetized mice were transcardially perfused with $4 \%$ paraformaldehyde in phosphate-buffered saline (PFA/PBS), followed by brain removal and incubation in $4 \%$ PFA/PBS for $24 \mathrm{~h}$ for fixation. Fixed brains were sectioned $(100 \mu \mathrm{m})$ using a vibratome (VT1200S, Leica, Germany) and subjected to immunofluorescence staining for IRSp53. The following antibodies were purchased commercially: BAIAP2/IRSp53 antibody (1:1,000, Atlas, rabbit, HPA023310), and $\alpha$-tubulin antibody $(1: 10,000$, Sigma, mouse, T9026). For immunoblotting, secondary antibodies for BAIAP2/IRSp53 and $\beta$-tubulin antibodies were donkey anti-rabbit antibody with $800 \mathrm{~nm}$ detection (LiCor, 1:10,000) and donkey anti-mouse antibody with HRP (Jackson, 1:10,000), respectively.

\section{Fluorescent in situ Hybridization}

Frozen sections ( $14 \mu \mathrm{m}$ thick) were cut coronally through the hippocampal formation. The sections were thaw-mounted onto Superfrost Plus Microscope Slides (Thermo Fisher Scientific, Waltham, MA, USA; 12-550-15). The sections were fixed in $4 \%$ formaldehyde for $10 \mathrm{~min}$, dehydrated in increasing concentrations of ethanol for $5 \mathrm{~min}$, and finally air-dried. Tissues were then pretreated for protease digestion for $10 \mathrm{~min}$ at room temperature. For RNA detection, incubations with different amplifier solutions were performed in a HybEZ hybridization oven (ACDBio, Newark, CA, USA) at $40^{\circ} \mathrm{C}$. The probes used in this study were three synthetic oligonucleotides complementary to the nucleotide (nt) sequence $2-1,268$ of Mm-Baiap2-C1, nt 464-1,415 of Mm-Slc17a7/Vglut1-C2, nt 1986-2,998 of Mm-Slc17a6/Vglut2-C3, nt 62-3,113 of MmGad1-C3, nt 552-1,506 of Mm-Gad2-C2 (ACDBio, Newark, CA, USA). The labeled probes were conjugated to Atto 550 (C1), Alexa Fluor 488 (C2), and Atto 647 (C3). The sections were hybridized at $40^{\circ} \mathrm{C}$ with labeled probe mixtures $(\mathrm{C} 1+\mathrm{C} 2+\mathrm{C} 3)$ per slide for $2 \mathrm{~h}$. Then the non-specifically hybridized probes were removed by washing the sections, three times each in $1 \times$ wash buffer at room temperature for $2 \mathrm{~min}$. Amplification steps involved sequential incubations with Amplifier 1-FL for $30 \mathrm{~min}$, Amplifier 2-FL for $15 \mathrm{~min}$, Amplifier 3-FL for $30 \mathrm{~min}$, and Amplifier 4 Alt B-FL at $40^{\circ} \mathrm{C}$ for $15 \mathrm{~min}$. Each amplifier solution was removed by washing three times with $1 \times$ wash buffer for $2 \mathrm{~min}$ at room temperature. Fluorescent images were acquired using TCS SP8 Dichroic/CS (Leica), and the ImageJ program $(\mathrm{NIH})$ was used to analyze the images.

\section{Statistics}

Statistical data analysis was performed using Prism 6 (GraphPad). Data normality was determined using the Shapiro-Wilk normality test. Data with normal distribution were analyzed using Student's $t$-test and analysis of variance (ANOVA), followed by post hoc tests. Data failing the normality test were analyzed using the Mann-Whitney test. ROUT method was used to exclude outliers with a Q coefficient of $1 \%$. Exact 

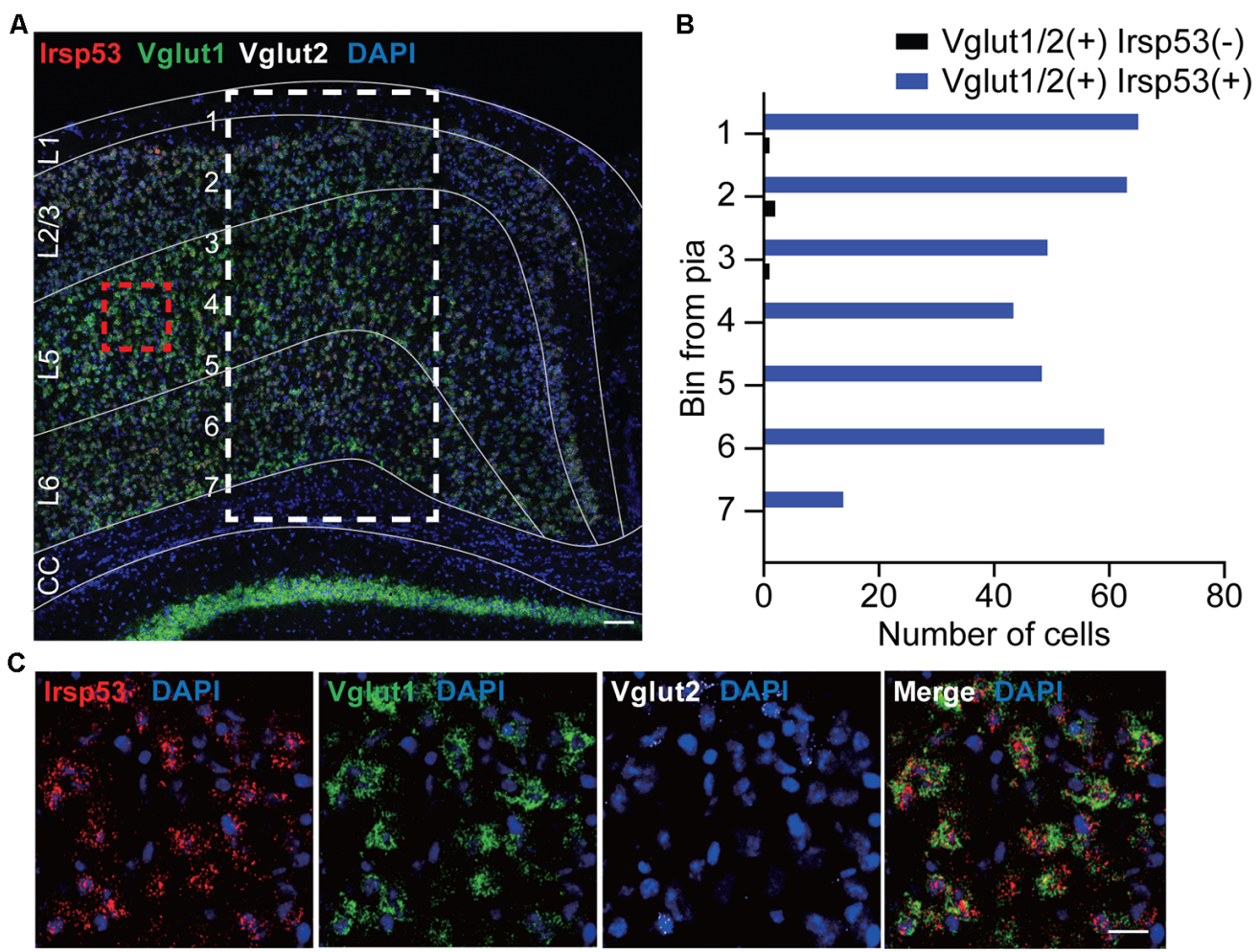

D

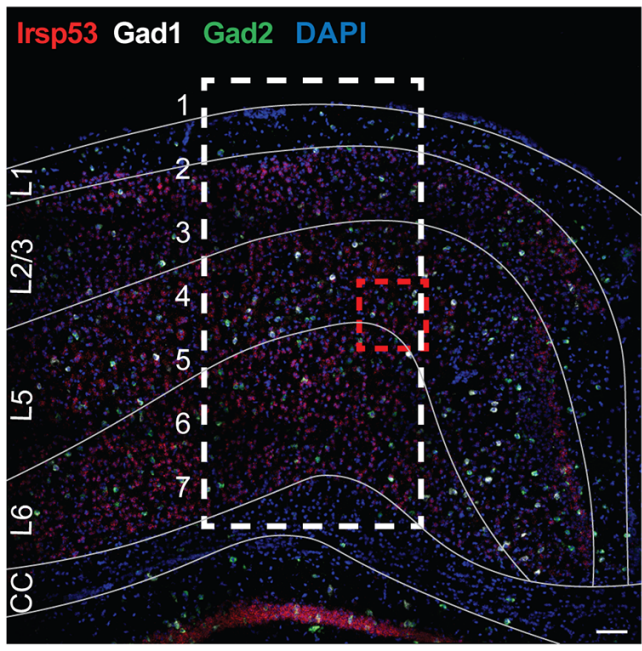

$\mathbf{E}$
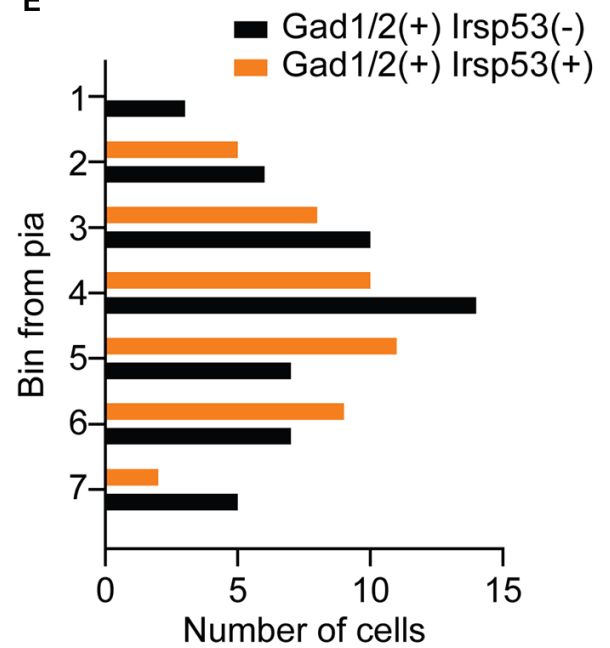

$\mathbf{F}$
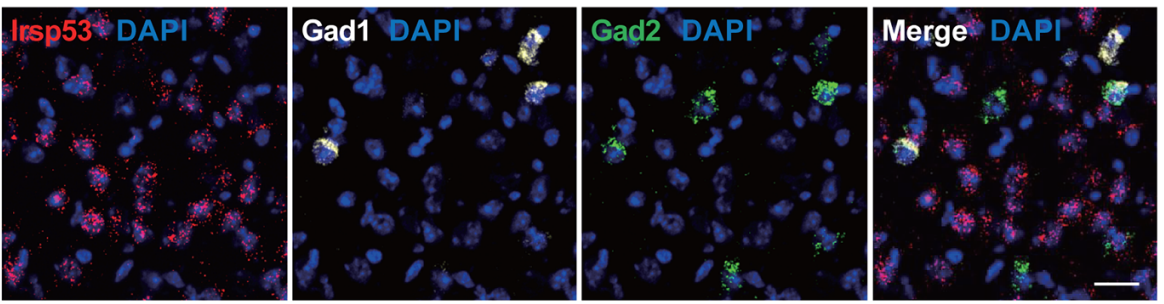

FIGURE 1 | Irsp53 mRNAs are primarily detected in glutamatergic but minimally in GABAergic neurons in the cortex. (A-F) Coronal sections of WT mice (8 weeks) were subjected to fluorescence in situ hybridization. Note that Irsp53/Baiap2 mRNAs are detected in Vglut1/2-positive glutamatergic neurons but minimally in Gad1/2-positive GABAergic neurons in the motor and somatosensory cortex. DAPI was used for nuclear staining. Red dashed line boxes were enlarged to show the levels of neuronal colabelings, and white dashed line boxes with subdivisions across cortical depth were used to quantify the colabelings. L1, cortical layer 1; CC, corpus callosum. Scale bar, $100 \mu \mathrm{m}$ (A,D) and $25 \mu \mathrm{m}(\mathbf{C}, \mathbf{F})$ 
A Irsp53/Baiap2 targeting strategy

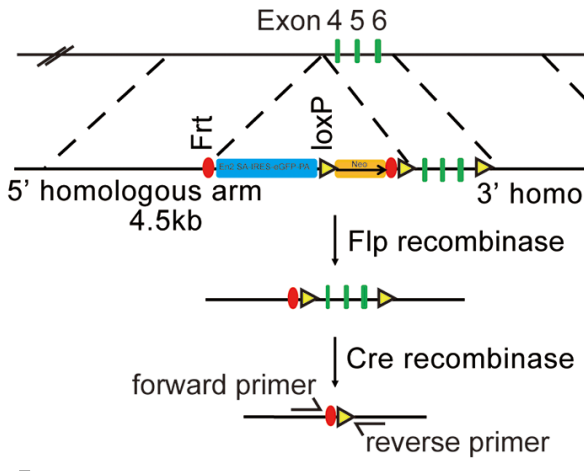

D
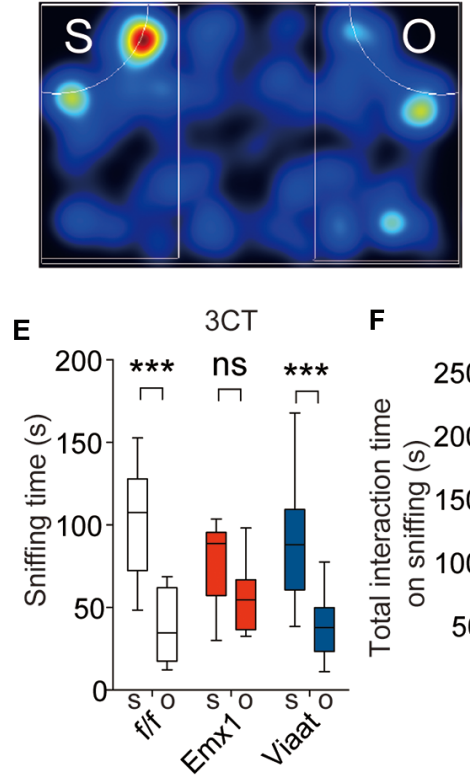

$\mathbf{F}$

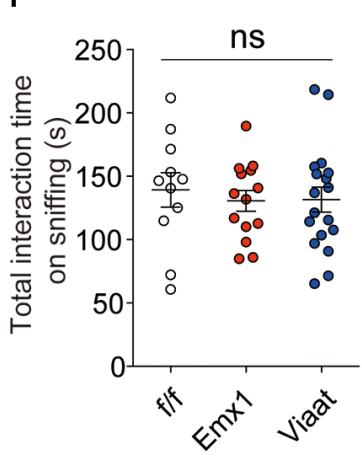

J

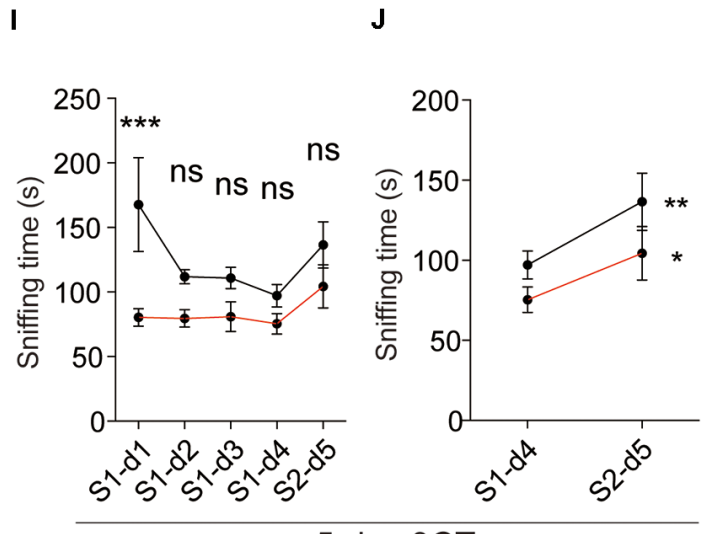

B

flox/WT flox/flox flox/flox

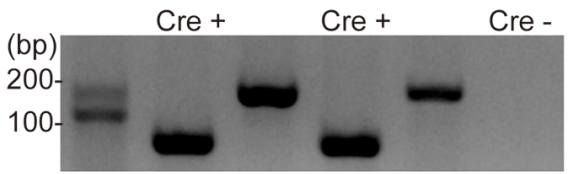

C

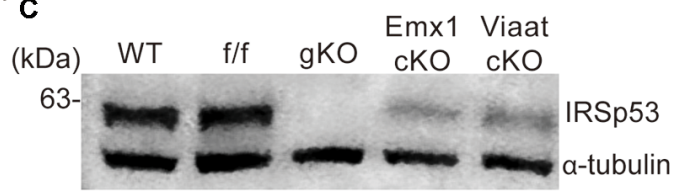

Emx1

cKO
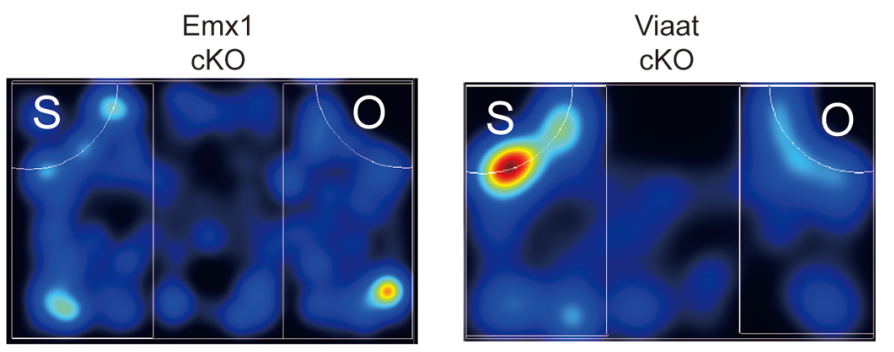

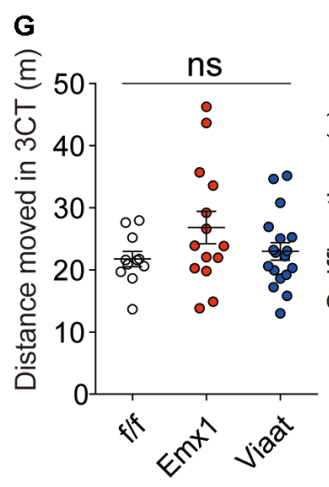

H

$\mathbf{K}$

OFT

L

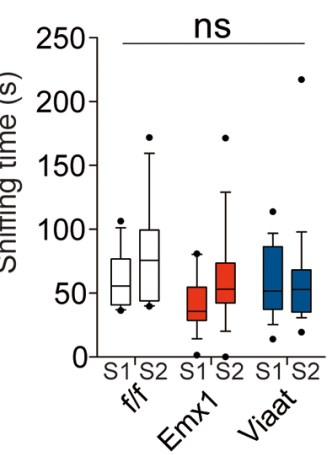

ns
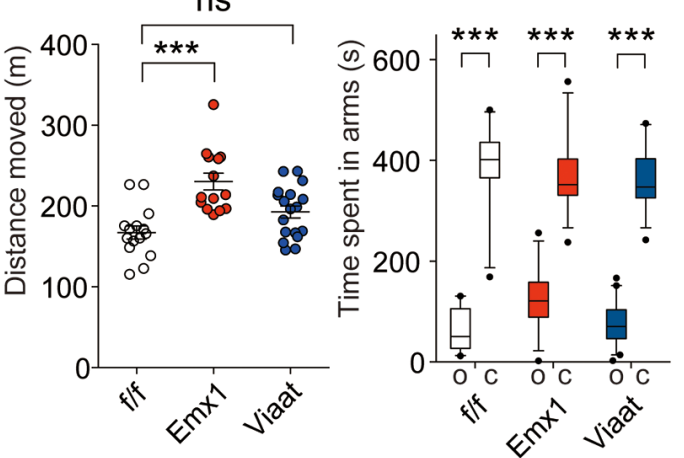

5-day 3CT

FIGURE 2 | Irsp53 deletion in glutamatergic but not GABAergic neurons induces social deficits and hyperactivity. (A) Schematic for conditional Irsp53/Baiap2

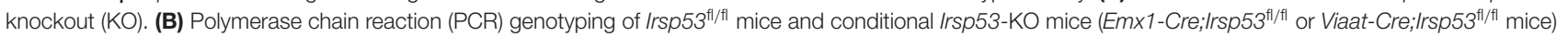
using primer sets directed for the Irsp53/Baiap2 allele and Cre recombinase. The two bands in the WT/flox lane represent PCR products from Irsp53 alleles with and without the Frt + LoxP sites. (C) Levels of IRSp53 proteins in global IRSp53-KO (gKO) mice, Emx1-Cre;/rsp53/f/fl mice (Emx1 cKO), and Viaat-Cre;/rsp53 $3^{\mathrm{fl} / \mathrm{fl}}$

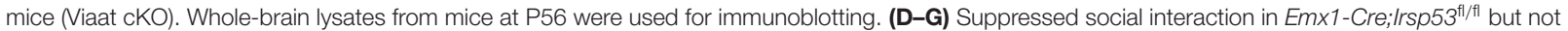




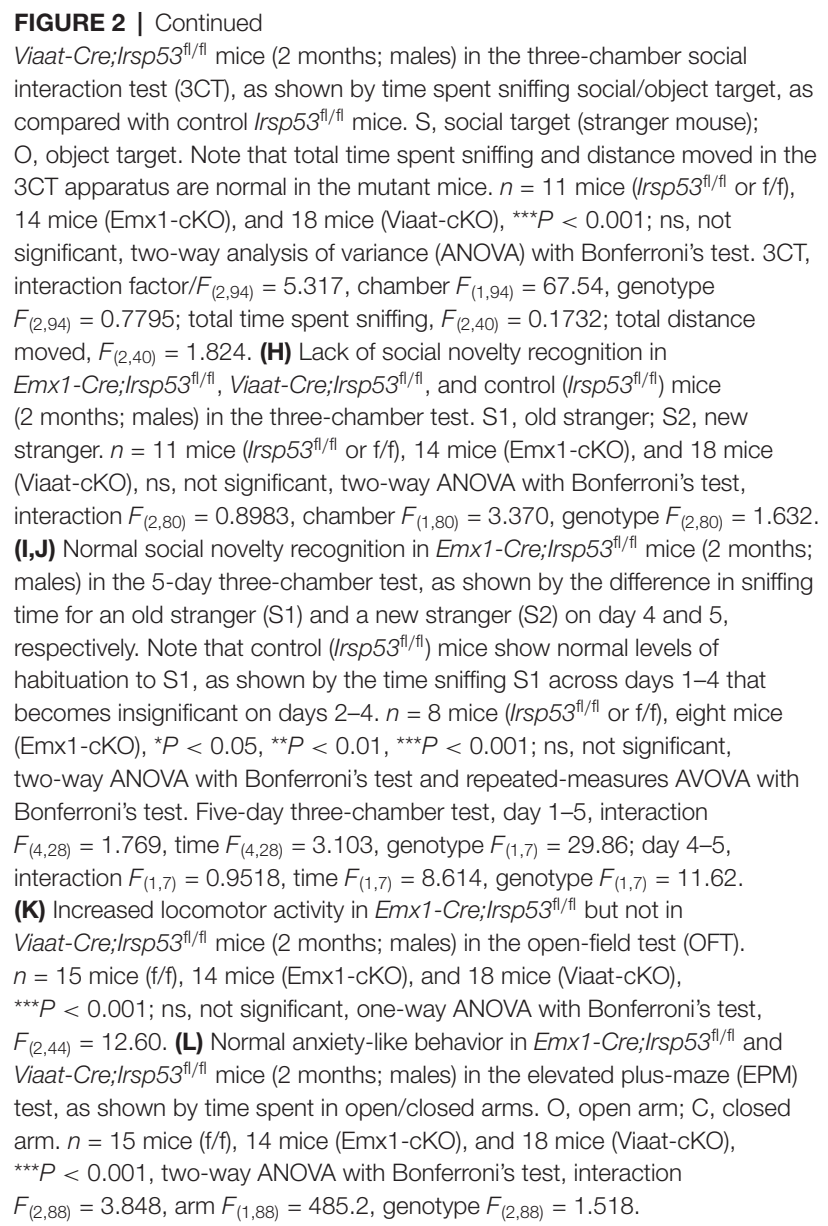

numbers of mice used and the statistical details are shown in Supplementary Table S1.

\section{RESULTS}

\section{Irsp53 mRNA Expression in Glutamatergic and GABAergic Neurons in the Cortex}

To explore specific brain cell types that contribute to social deficits and hyperactivity observed in global Irsp53-KO mice (Chung et al., 2015), we first determined IRSp53 expression in glutamatergic and GABAergic neurons by in situ fluorescence hybridization. Irsp53 mRNA was readily detected in Vglut1/2positive glutamatergic neurons in the cortex, but it was minimally detectable in Gad1/2-positive GABAergic neurons (Figures 1A-F). Quantitative analysis indicated that colabelings of Irsp53 and Vglut1/2 mRNAs were not different across the depth of cortical layers, whereas colabelings of Irsp53 and Gad1/2 mRNAs, although sparse $(\sim 13 \%$ of the Irsp53Vglut1/2 colabelings in number), were stronger in middle layers. These results are consistent with the reported expression of IRSp53 protein primarily in glutamatergic but not GABAergic neurons in the cortex and hippocampus, although IRSp53 protein is also detectable in striatal and cerebellar GABAergic neurons (Burette et al., 2014).

\section{Irsp53 Deletion in Dorsal Telencephalic Glutamatergic but Not GABAergic Neurons Induces Social Deficits and Hyperactivity}

For conditional Irsp53 $\mathrm{KO}$ in glutamatergic or GABAergic neurons, we generated a novel mouse line in which exons 4-6 of Irsp53 are floxed (Irsp53 $3^{\mathrm{fl} / \mathrm{fl}}$ mice) and crossed them with Emx1-Cre (Jax005628; dorsal telencephalic glutamatergic; Gorski et al., 2002) and Viaat-Cre (Jax017535; Chao et al., 2010) mice, respectively (Figure 2A). The resulting conditional Irsp53-

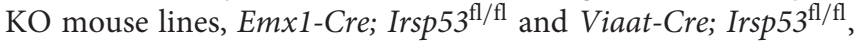
were verified by PCR genotyping and immunoblot analysis (Figures 2B,C). IRSp53 protein levels in Emx1-Cre; Irsp $53^{\mathrm{fl} / \mathrm{fl}}$ and Viaat-Cre; Irsp5 $53^{\mathrm{fl} / \mathrm{fl}}$ whole brains were $\sim 29 \pm 4 \%$ and $\sim 64 \pm 4 \%$ of WT values, respectively. Appropriate expression of Cre in the mouse lines used in this study was confirmed by crossing with a reporter mouse line (Ai9 tdTomato line; JAX 007909; Madisen et al., 2010; Supplementary Figure S1).

In behavioral experiments performed using male mice, Emx1Cre; Irsp $53^{\mathrm{fl} / \mathrm{fl}}$ mice displayed impaired social interaction in the three-chamber test compared with control $\left(\operatorname{Irsp} 53^{\mathrm{fl} / \mathrm{fl}}\right)$ mice without Cre expression (Figures 2D,E). These changes did not accompany altered total social interaction or locomotor activity in the three-chamber apparatus (Figures 2F,G).

Changes in social novelty recognition during the threechamber test could not be determined because control Irsp $53^{\mathrm{fl} / \mathrm{fl}}$ mice did not prefer to explore a novel stranger (Figure $2 \mathbf{H}$ ). However, an additional test for social novelty recognition termed 5-day three-chamber test, where a subject mouse was exposed to the first stranger mouse for four consecutive days for full habituation followed by exposure to the second stranger mouse on day 5 (Bariselli et al., 2018), Emx1-Cre;Irsp53 ${ }^{\mathrm{fl} / \mathrm{fl}}$ mice displayed normal social novelty recognition that is comparable to that of control (Irsp53 $\left.3^{\mathrm{fl} / \mathrm{fl}}\right)$ mice (Figures 2I,J).

Emx1-Cre;Irsp53 $3^{\mathrm{fl} / \mathrm{fl}}$ mice displayed hyperactivity in the OFT but normal anxiety-like behavior in the EPM test (Figures $2 \mathbf{K}, \mathbf{L}$ ). Viaat-Cre;Irsp53 $3^{\mathrm{fl} / \mathrm{fl}}$ mice showed no detectable changes in social interaction, locomotor activity, or anxiety-like behavior (Figures 2D,E,L). Control (Irsp53 $3^{\mathrm{fl} / \mathrm{fl}}$ ) mice showed normal social interaction and locomotor activity, compared with WT mice (without Irsp53 $3^{\mathrm{fl} / \mathrm{fl}}$ and Cre alleles; Supplementary Figures 2A,B). In addition, mice expressing Cre alone (Emx1-Cre and Viaat-Cre) showed normal social interaction, locomotion, or anxiety-like behavior (Supplementary Figures 2C-E). Therefore, Irsp53 KO in dorsal telencephalic glutamatergic, but not GABAergic, neurons leads to social deficits and hyperactivity in mice, similar to those in global Irsp53-KO mice (Chung et al., 2015).

\section{Emx1-Cre; Irsp53 ${ }^{\mathrm{fl} / \mathrm{fl}}$ and Viaat-Cre; Irsp53 fl/fl Mice Show Distinct Changes in Synaptic Transmission and Intrinsic Excitability in mPFC Pyramidal Neurons}

To explore mechanisms underlying the social deficits and hyperactivity in Emx1-Cre; Irsp53 $3^{\mathrm{fl} / \mathrm{fl}}$ mice, we analyzed synaptic and neuronal properties in the $\mathrm{mPFC}$, a brain region that displayed decreased excitatory synapse density in global Irsp53- 
A

\section{$500 \mathrm{~ms}$ \\ $\mathrm{f} / \mathrm{fmIPSC} / \mathrm{mEPSC} 10 \mathrm{pA} \quad$ Emx $1 \mathrm{mIPSC} / \mathrm{mEPSC} \quad$ Viaat mIPSC/mEPSC}

mPFC mEPSC

MPFC mIPSC
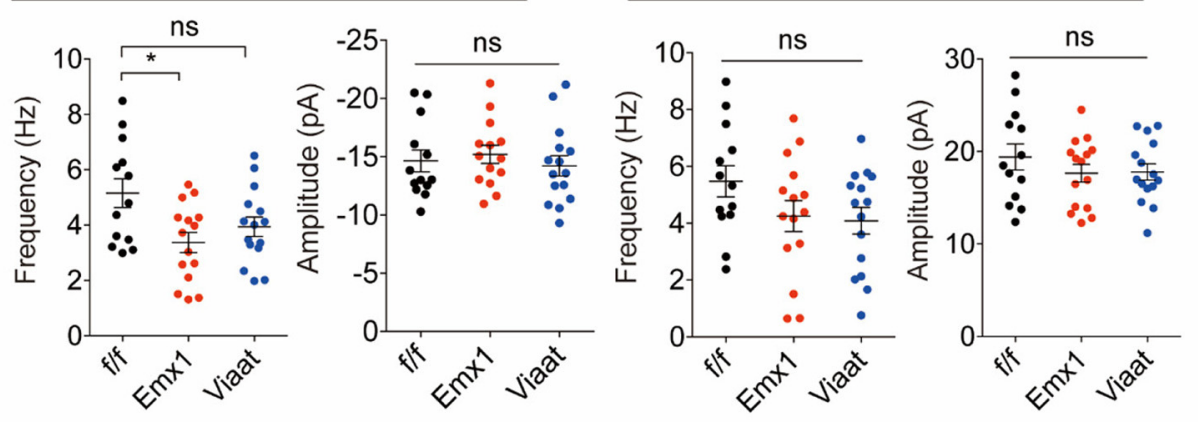

B
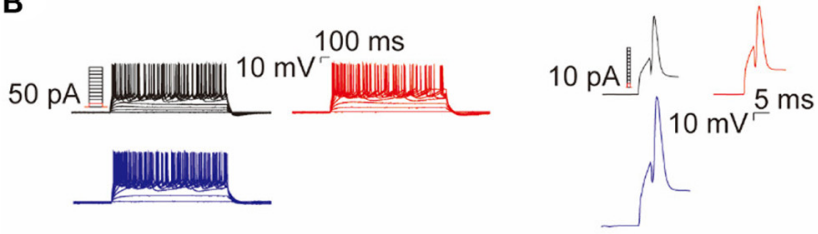

AP threshold

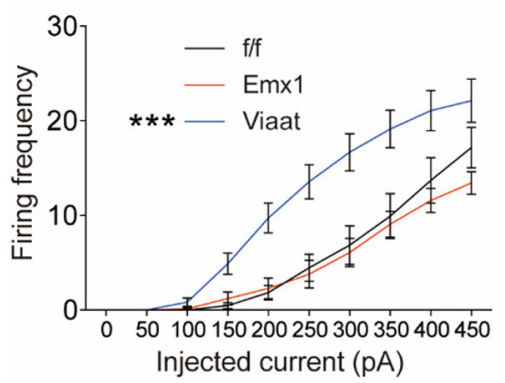

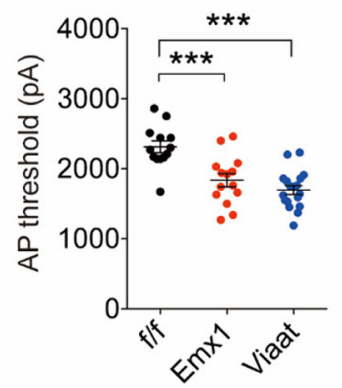

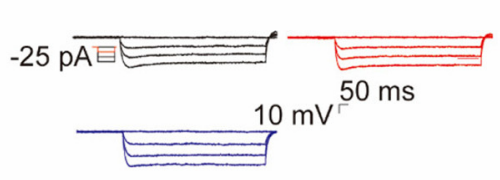

Input resistance

$\mathrm{pA}$

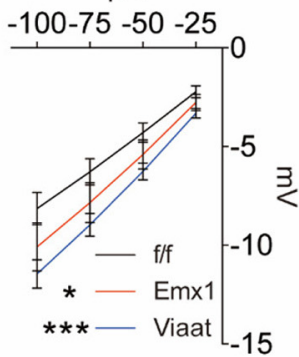

C

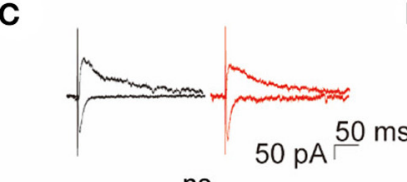

D

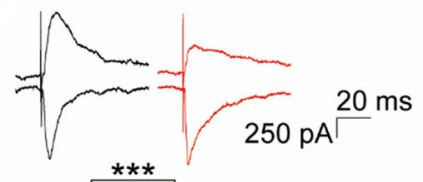

E

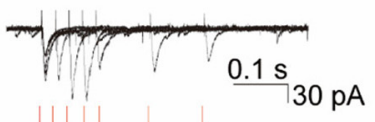

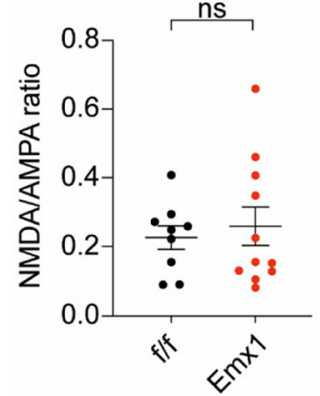
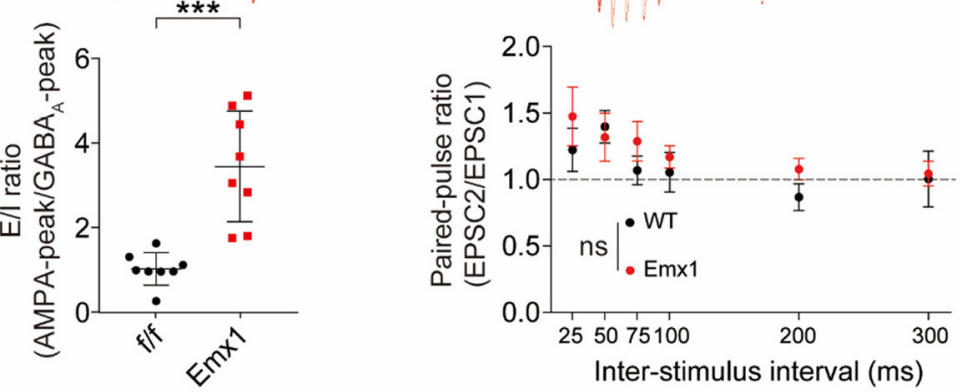

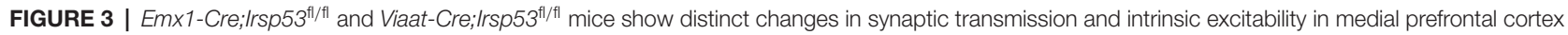
(mPFC) pyramidal neurons. (A) Miniature excitatory postsynaptic currents (mEPSCs) and miniature inhibitory postsynaptic currents (mIPSCs) in layer $V$ pyramidal

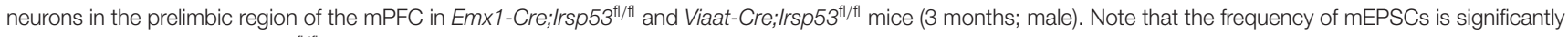
decreased in Emx1-Cre;/rsp53 ${ }^{\mathrm{fl} / \mathrm{fl}}$ mice. $n=13$ neurons from three mice for f/f-mEPSC, 14, 3 for Emx1-mEPSC, 15, 3 for Viaat-mEPSC, 13, 3 for f/f-mIPSC, 15, 3 for Emx1-mIPSC, and 15, 3 for Viaat-mIPSC, ${ }^{\star} P<0.05$, ns, not significant, one-way ANOVA with Bonferroni's test. mEPSC frequency, $F(2,39)=4.119$; mEPSC amplitude, $F_{(2,39)}=0.342$; mIPSC frequency, $F_{(2,40)}=2.012$; mIPSC amplitude, $F_{(2,40)}=0.7806$. (B) Intrinsic excitability in layer $V$ pyramidal neurons in the prelimbic 


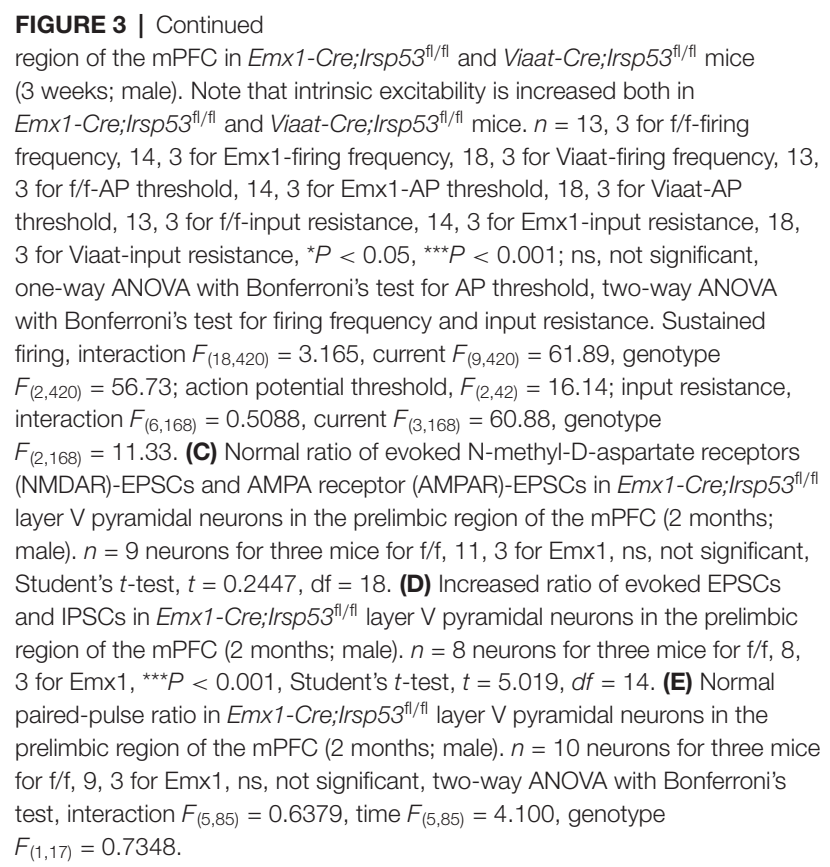

KO mice (Chung et al., 2015). The frequency but not amplitude of mEPSCs in the Emx1-Cre; Irsp53 $3^{\mathrm{fl} / \mathrm{fl}} \mathrm{mPFC}$ (layer V pyramidal neurons in the prelimbic area) was decreased, whereas mIPSCs were normal (Figure 3A), in line with the reported decrease in excitatory synaptic transmission and dendritic spine density in $\mathrm{mPFC}$ pyramidal neurons from Irsp53-null mice (Chung et al., 2015). In addition, these neurons showed moderately increased intrinsic excitability, as shown by action potential threshold and input resistance (Figure 3B), likely to compensate for the decreased excitatory synaptic input. In Viaat-Cre; $\operatorname{Irsp} 53^{\mathrm{fl} / \mathrm{fl}}$ mice, however, mEPSCs or mIPSCs were normal in layer $\mathrm{V} \mathrm{mPFC}$ neurons (Figure $3 \mathrm{~A}$ ). Intriguingly, the intrinsic excitability was strongly increased, as shown by currentfiring curve, action potential threshold, and input resistance (Figure 3B).

When evoked synaptic transmission was measured, the ratio of NMDAR-mediated EPSCs and AMPA receptor (AMPAR)mediated EPSCs was not altered in Emx1-Cre; Irsp $53^{\mathrm{fl} / \mathrm{fl}}$ layer V pyramidal neurons (Figure 3C). These results collectively suggest that Irsp53 deletion in glutamatergic neurons leads to reduced spontaneous excitatory but not inhibitory synaptic transmission, increased ratio of evoked EPSCs/IPSCs, and increased neuronal excitability without affecting evoked NMDAR-EPSC/AMPAREPSC ratio in layer $\mathrm{V} \mathrm{mPFC}$ neurons.

\section{Male and Female Emx1-Cre; Irsp53 ${ }^{\mathrm{fl} / \mathrm{fl}}$ Mice Show Distinct Changes in Synaptic Transmission and Behaviors}

The abovementioned behavioral and electrophysiological results were obtained from male Emx1-Cre; Irsp53 ${ }^{\mathrm{fl} / \mathrm{fl}}$ mice. Given that male-female differences could affect these phenotypes, we measured social interaction and locomotor activity in Emx1Cre;Irsp53 $3^{\mathrm{fl} / \mathrm{fl}}$ mice. Intriguingly, female Emx1-Cre;Irsp53 $3^{\mathrm{fl} / \mathrm{fl}}$ mice showed normal three-chamber social interaction in the three-chamber test, although there was a decreasing tendency, as compared with control $\left(\operatorname{Irsp} 53^{\mathrm{fl} / \mathrm{fl}}\right)$ mice (Figure 4A), indicative of male-female difference in social interaction. In contrast, female Emx1-Cre; Irsp $53^{\mathrm{fl} / \mathrm{fl}}$ mice showed strong hyperactivity in the OFT (Figure 4B), similar to male Emx1-Cre;Irsp53 $3^{\mathrm{fl} / \mathrm{fl}}$ mice.

When excitatory synaptic transmission was measured in layer $\mathrm{V}$ pyramidal neurons in the prelimbic area of the $\mathrm{mPFC}$ from female Emx1-Cre;Irsp53 $3^{\mathrm{fl} / \mathrm{fl}}$ mice, there was a decrease in the amplitude, but not frequency, of mEPSCs in female mutant neurons, compared with WT neurons (Figure 4C), which contrasts with the decreased frequency but not amplitude of mEPSCs in male mutant neurons (Figure 3A). In addition, there were no genotype differences in the ratio of evoked EPSCs/IPSCs or the paired-pulse ratio in layer $\mathrm{V}$ pyramidal neurons (Figures 4D,E). These results collectively suggest that Irsp53 deletion induces distinct changes in behaviors and excitatory synaptic transmission in the mPFC.

\section{DISCUSSION}

We attempted here to restrict Irsp53 deletion to Emx1-positive glutamatergic and Viaat-positive GABAergic neurons to investigate the impact of IRSp53 $\mathrm{KO}$ in the respective neurons on mouse behaviors and synaptic/neuronal properties. Irsp53 $\mathrm{KO}$ in Emx1-positive dorsal telencephalic glutamatergic neurons leads to both social interaction deficits and hyperactivity, two key behavioral phenotypes observed in global Irsp53-KO mice (Chung et al., 2015), whereas Irsp53 KO in Viaat-positive GABAergic neurons does not affect social interaction or hyperactivity. Therefore, Irsp53 expression in glutamatergic neurons in the cortex, where Emx1 is strongly expressed, seems to be important for normal social interaction and locomotor activity. This is in line with the well-known importance of the PFC in the regulation of social cognition and interaction, previously reported in studies with human subjects as well as WT and mutant mice carrying ASD- and schizophrenia-related gene mutations (Ernst et al., 1997; Mundy, 2003; Pierce et al., 2004; Carper and Courchesne, 2005; Amodio and Frith, 2006; Gilbert et al., 2008; Rinaldi et al., 2008; Shalom, 2009; Courchesne et al., 2011; Yizhar et al., 2011; Testa-Silva et al., 2012; Liang et al., 2015; Barak and Feng, 2016; Ko, 2017; Selimbeyoglu et al., 2017; Cao et al., 2018; Pirone et al., 2018; Wang et al., 2018, 2019; Guo et al., 2019; Lazaro et al., 2019; Phillips et al., 2019; Yoo et al., 2019).

Irsp53 $\mathrm{KO}$ restricted to Emx1-positive glutamate neurons induces decreased mEPSC frequency, decreased NMDA/AMPA ratio, and increased $\mathrm{E} / \mathrm{I}$ ratio in layer $\mathrm{V}$ pyramidal neurons in the prelimbic region of the mPFC. These changes are associated with moderately increased neuronal excitability. Whether these changes alter the output function of the mutant layer $\mathrm{V}$ pyramidal neurons under basal or social conditions would require additional analyses. However, the $\mathrm{mPFC}$ is known to receive afferent projections from various brain regions (Riga et al., 2014; Root et al., 2015; Murugan et al., 2017; Park and Moghaddam, 2017; Knowland and Lim, 2018). In particular, the prelimbic region of the $\mathrm{mPFC}$ receives 


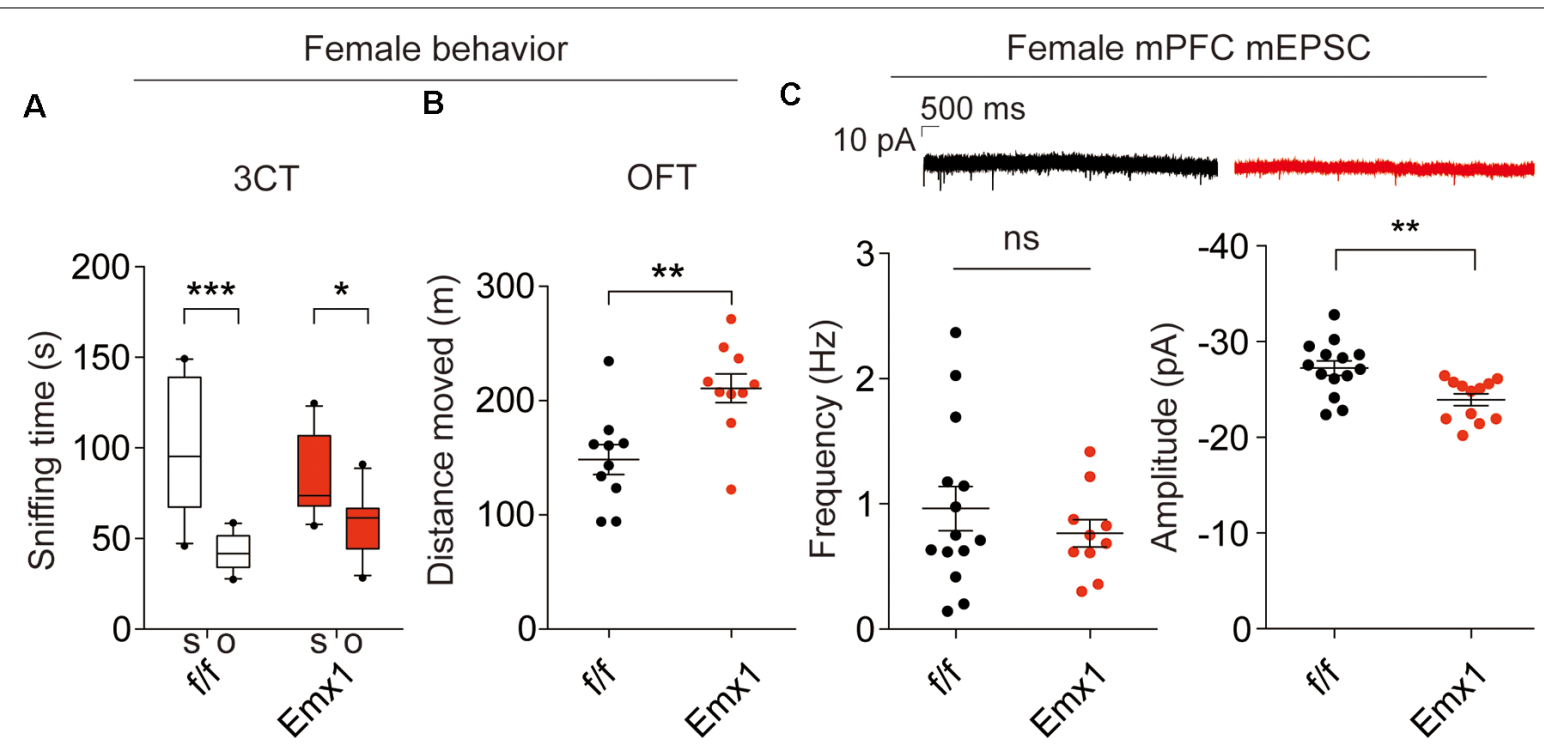

Female $\mathrm{mPFC}$ E/I ratio and paired-pulse ratio

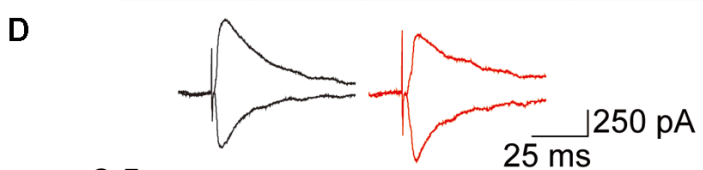

E
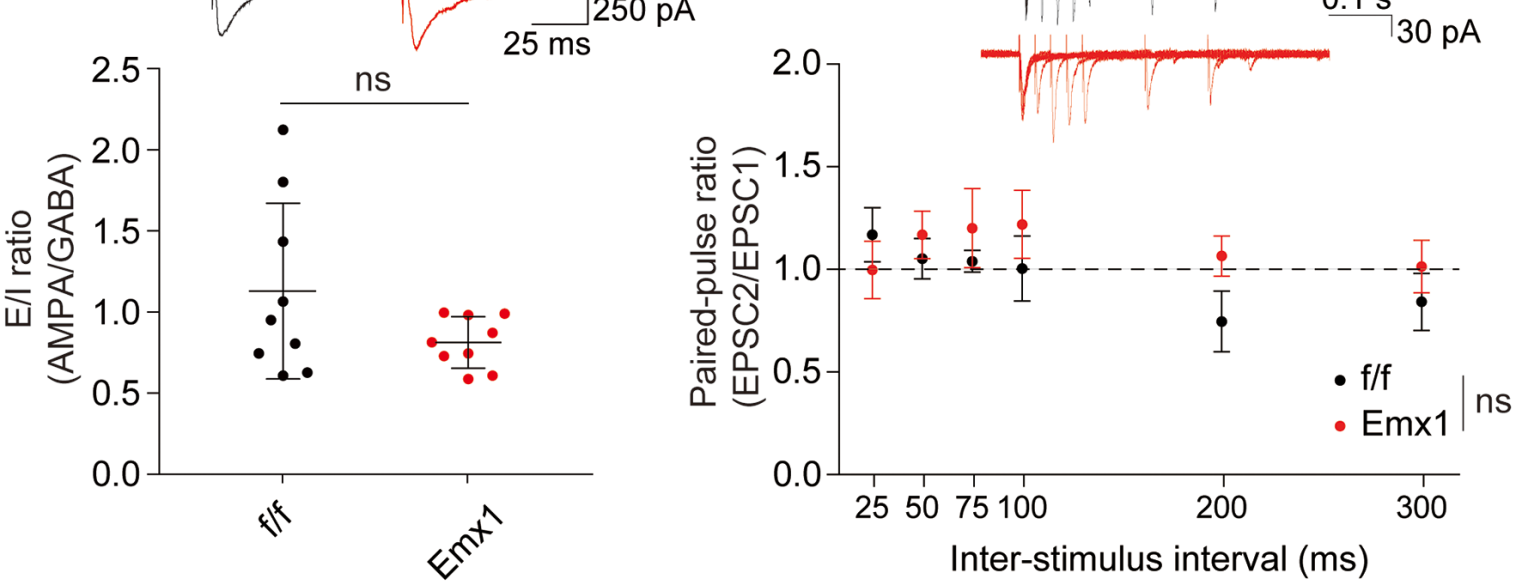

FIGURE 4 | Female Emx1-Cre;/rsp53 ${ }^{\mathrm{fl} / \mathrm{fl}}$ mice show distinct changes in synaptic transmission and behaviors. (A) Normal social interaction in female

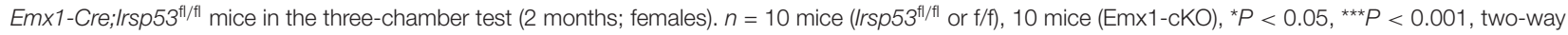
ANOVA with Bonferroni's test, interaction $F_{(1,36)}=4.035$, chamber $F_{(1,36)}=31.58$, genotype $F_{(1,36)}=0.0003937$. (B) Hyperactivity in female Emx1-Cre; Irsp53 fl/fl mice in the OFT (2 months; females). $n=10$ mice (Irsp53 fl/fl or f/f), 10 mice (Emx1-cKO), ${ }^{* \star} P<0.01$, Student's $t$-test, $t=3.434, d f=18$. (C) Decreased amplitude but normal frequency of mEPSCs in layer $V$ pyramidal neurons in the prelimbic region of the mPFC in Emx1-Cre;/rsp53fl/fl (3 months; females). $n=14$ neurons from three mice for f/f-mEPSC, 10, 3 for Emx1-mEPSC in mPFC, ${ }^{\star \star} P<0.01$; ns, not significant, Mann-Whitney test for frequency, Student's $t$-test for amplitude. mEPSC frequency, Mann-U 62; mEPSC amplitude, $t=3.278, d f=24$. (D) Normal ratio of evoked EPSCs and IPSCs in layer $V$ pyramidal neurons in the prelimbic region of the $\mathrm{mPFC}$ in female Emx1-Cre; Irsp53 ${ }^{\mathrm{fl} / \mathrm{fl}}$ mice (2-3 months; females). $n=9$ neurons for three mice for $\mathrm{f} / \mathrm{f}, 9$, 3 for Emx1, ns, not significant, Student's $t$-test, $t=1.675$, $d f=16$. (E) Normal paired-pulse ratio in layer $\vee$ pyramidal neurons in the prelimbic region of the mPFC in female Emx1-Cre;/rsp53 ${ }^{f / f l}$ (2-3 months; females). $n=6$ neurons for three mice for f/f, 6,3 for Emx1, ns, not significant, two-way ANOVA with Bonferroni's test, interaction $F_{(5,90)}=0.8666$, time $F_{(5,90)}=0.9748$, genotype $F_{(1,18)}=0.6927$.

strong afferent projections from limbic regions of the cortex as well as other subcortical areas, including basal forebrain, thalamus, amygdala, hypothalamus, and midbrain (Hoover and Vertes, 2007). In addition, layer V pyramidal neurons in the prelimbic area project to various subcortical regions, including lateral hypothalamus, striatum, and basolateral amygdala (Sesack et al., 1989; Gabbott et al., 2005). Therefore, the altered spontaneous and evoked synaptic transmission and intrinsic excitability of the mutant layer $\mathrm{V}$ pyramidal neurons might change their output functions and contribute to social deficits and hyperactivity observed in Emx1-Cre; Irsp $53^{\mathrm{fl} / \mathrm{fl}}$ mice. 
Emx1-Cre; Irsp53 $3^{\mathrm{fl} / \mathrm{fl}}$ males show strong social deficits whereas females show only modestly suppressed social interaction, while they both show comparable hyperactivity. This suggests that the hyperactivity is not the key confounding factor contributing to the social deficits. Notably, spontaneous excitatory synaptic transmission is distinctly changed in layer $\mathrm{V}$ pyramidal neurons in the prelimbic area in male and female Emx1-Cre;Irsp53 $3^{\mathrm{fl} / \mathrm{fl}}$ mice; decreased mEPSC frequency in male neurons and decreased mEPSC amplitude (not frequency) in female neurons. This difference, although intriguing, is less likely to induce a qualitative difference in the output function of these neurons. Importantly, however, the E/I ratio of evoked synaptic transmission was increased in male, but female, layer $\mathrm{V}$ pyramidal neurons. Although further details remain to be determined, these results are in line with the reported association of altered E/I ratio in cortical neurons with social deficits (Yizhar et al., 2011; Nelson and Valakh, 2015; Lee et al., 2017; Selimbeyoglu et al., 2017). In addition, these results add to the emerging notion that non-sex-differential factors such as synaptic transmission and neuronal properties (relative to sex-differential factors such as hormone and $\mathrm{X}-\mathrm{Y}$ chromosomes) may contribute to the male-female phenotypic differences in animal models of autism (Werling and Geschwind, 2013; Barak and Feng, 2016; Lo et al., 2016; Werling et al., 2016; Jung et al., 2018). Last, our data indicate that GABAergic neuronal deletion of IRSp53 in male mice minimally affects social and locomotor activities. However, this does not exclude the possibility that female mice with the same mutation show some positive electrophysiological and behavioral phenotypes.

In conclusion, our data suggest that Irsp53 KOs restricted to glutamatergic neurons and GABAergic neurons and in male and

\section{REFERENCES}

Amodio, D. M., and Frith, C. D. (2006). Meeting of minds: the medial frontal cortex and social cognition. Nat. Rev. Neurosci. 7, 268-277. doi: $10.1038 /$ nrn 1884

Barak, B., and Feng, G. (2016). Neurobiology of social behavior abnormalities in autism and Williams syndrome. Nat. Neurosci. 19, 647-655. doi: 10.1038/nn. 4276

Bariselli, S., Hörnberg, H., Prévost-Solié, C., Musardo, S., Hatstatt-Burklé, L., Scheiffele, P., et al. (2018). Role of VTA dopamine neurons and neuroligin 3 in sociability traits related to nonfamiliar conspecific interaction. Nat. Commun. 9:3173. doi: 10.1038/s41467-018-05382-3

Bobsin, K., and Kreienkamp, H. J. (2016). Severe learning deficits of IRSp53 mutant mice are caused by altered NMDA receptor dependent signal transduction. J. Neurochem. 136, 752-763. doi: 10.1111/jnc. 13428

Burette, A. C., Park, H., and Weinberg, R. J. (2014). Postsynaptic distribution of IRSp53 in spiny excitatory and inhibitory neurons. J. Comp. Neurol. 522, 2164-2178. doi: $10.1002 / \mathrm{cne} .23526$

Cao, W., Lin, S., Xia, Q. Q., Du, Y. L., Yang, Q., Zhang, M. Y., et al. (2018). Gamma oscillation dysfunction in mPFC leads to social deficits in neuroligin 3 R451C knockin mice. Neuron 98:670. doi: 10.1016/j.neuron.2018. 04.025

Carper, R. A., and Courchesne, E. (2005). Localized enlargement of the frontal cortex in early autism. Biol. Psychiatry 57, 126-133. doi: 10.1016/j.biopsych. 2004.11.005 female mice lead to distinct behavioral deficits and changes in synaptic and neuronal properties in the mPFC.

\section{DATA AVAILABILITY STATEMENT}

All datasets generated for this study are included in the article/Supplementary Material.

\section{ETHICS STATEMENT}

The animal study was reviewed and approved by the Committee of Animal Research at Korea Advanced Institute of Science and Technology (KAIST).

\section{AUTHOR CONTRIBUTIONS}

YK performed most of the experiments except for FISH experiments. YK, YN, and $\mathrm{KK}$ performed the electrophysiological experiments. EY performed the FISH experiments. YK, HK, and EK designed the experiments and wrote the manuscript.

\section{FUNDING}

This work was supported by the Institute for Basic Science (IBSR002-D1 to EK).

\section{SUPPLEMENTARY MATERIAL}

The Supplementary Material for this article can be found online at: https://www.frontiersin.org/articles/10.3389/fncel. 2020.00023/full\#supplementary-material.

Celestino-Soper, P. B., Shaw, C. A., Sanders, S. J., Li, J., Murtha, M. T., ErcanSencicek, A. G., et al. (2011). Use of array CGH to detect exonic copy number variants throughout the genome in autism families detects a novel deletion in TMLHE. Hum. Mol. Genet. 20, 4360-4370. doi: 10.1093/hmg/ddr363

Chao, H. T., Chen, H., Samaco, R. C., Xue, M., Chahrour, M., Yoo, J., et al. (2010). Dysfunction in GABA signalling mediates autism-like stereotypies and Rett syndrome phenotypes. Nature 468, 263-269. doi: 10.1038/nature09582

Chen, B. T., Yau, H. J., Hatch, C., Kusumoto-Yoshida, I., Cho, S. L., Hopf, F. W., et al. (2013). Rescuing cocaine-induced prefrontal cortex hypoactivity prevents compulsive cocaine seeking. Nature 496, 359-362. doi: 10.1038/nature12024

Chung, W., Choi, S. Y., Lee, E., Park, H., Kang, J., Park, H., et al. (2015). Social deficits in IRSp53 mutant mice improved by NMDAR and mGluR5 suppression. Nat. Neurosci. 18, 435-443. doi: 10.1038/nn.3927

Courchesne, E., Mouton, P. R., Calhoun, M. E., Semendeferi, K., AhrensBarbeau, C., Hallet, M. J., et al. (2011). Neuron number and size in prefrontal cortex of children with autism. JAMA 306, 2001-2010. doi: 10.1001/jama. 2011.1638

Ernst, M., Zametkin, A. J., Matochik, J. A., Pascualvaca, D., and Cohen, R. M. (1997). Low medial prefrontal dopaminergic activity in autistic children. Lancet 350:638. doi: 10.1016/s0140-6736(05)63326-0

Fromer, M., Pocklington, A. J., Kavanagh, D. H., Williams, H. J., Dwyer, S., Gormley, P., et al. (2014). De novo mutations in schizophrenia implicate synaptic networks. Nature 506, 179-184. doi: 10.1038/nature12929

Gabbott, P. L., Warner, T. A., Jays, P. R., Salway, P., and Busby, S. J. (2005). Prefrontal cortex in the rat: projections to subcortical autonomic, motor, and limbic centers. J. Comp. Neurol. 492, 145-177. doi: 10.1002/cne.20738 
Gilbert, S. J., Bird, G., Brindley, R., Frith, C. D., and Burgess, P. W. (2008). Atypical recruitment of medial prefrontal cortex in autism spectrum disorders: an fMRI study of two executive function tasks. Neuropsychologia 46, 2281-2291. doi: 10.1016/j.neuropsychologia.2008.03.025

Gorski, J. A., Talley, T., Qiu, M., Puelles, L., Rubenstein, J. L., and Jones, K. R. (2002). Cortical excitatory neurons and glia, but not GABAergic neurons, are produced in the Emx1-expressing lineage. J. Neurosci. 22, 6309-6314. doi: 10.1523/JNEUROSCI.22-15-06309.2002

Guo, B., Chen, J., Chen, Q., Ren, K., Feng, D., Mao, H., et al. (2019). Anterior cingulate cortex dysfunction underlies social deficits in Shank3 mutant mice. Nat. Neurosci. 22, 1223-1234. doi: 10.1038/s41593-019-0445-9

Hoover, W. B., and Vertes, R. P. (2007). Anatomical analysis of afferent projections to the medial prefrontal cortex in the rat. Brain Struct. Funct. 212, 149-179. doi: 10.1007/s00429-007-0150-4

Jiang, Y. H., and Ehlers, M. D. (2013). Modeling autism by SHANK gene mutations in mice. Neuron 78, 8-27. doi: 10.1016/j.neuron.2013.03.016

Jung, H., Park, H., Choi, Y., Kang, H., Lee, E., Kweon, H., et al. (2018). Sexually dimorphic behavior, neuronal activity, and gene expression in Chd8-mutant mice. Nat. Neurosci. 21, 1218-1228. doi: 10.1038/s41593-018-0208-z

Kang, J., Park, H., and Kim, E. (2016). IRSp53/BAIAP2 in dendritic spine development, NMDA receptor regulation, and psychiatric disorders. Neuropharmacology 100, 27-39. doi: 10.1016/j.neuropharm. 2015.06.019

Kim, M. H., Choi, J., Yang, J., Chung, W., Kim, J. H., Paik, S. K., et al. (2009). Enhanced NMDA receptor-mediated synaptic transmission, enhanced long-term potentiation, and impaired learning and memory in mice lacking IRSp53. J. Neurosci. 29, 1586-1595. doi: 10.1523/JNEUROSCI.430608.2009

Knowland, D., and Lim, B. K. (2018). Circuit-based frameworks of depressive behaviors: the role of reward circuitry and beyond. Pharmacol. Biochem. Behav. 174, 42-52. doi: 10.1016/j.pbb.2017.12.010

Ko, J. (2017). Neuroanatomical substrates of rodent social behavior: the medial prefrontal cortex and its projection patterns. Front. Neural Circuits 11:41. doi: 10.3389/fncir.2017.00041

Lazaro, M. T., Taxidis, J., Shuman, T., Bachmutsky, I., Ikrar, T., Santos, R., et al. (2019). Reduced prefrontal synaptic connectivity and disturbed oscillatory population dynamics in the CNTNAP2 model of autism. Cell Rep. 27, 2567.e6-2578.e6. doi: 10.1016/j.celrep.2019.05.006

Lee, E. J., Choi, S. Y., and Kim, E. (2015). NMDA receptor dysfunction in autism spectrum disorders. Curr. Opin. Pharmacol. 20C, 8-13. doi: 10.1016/j.coph. 2014.10.007

Lee, E., Lee, J., and Kim, E. (2017). Excitation/inhibition imbalance in animal models of autism spectrum disorders. Biol. Psychiatry 81, 838-847. doi: 10.1016/j.biopsych.2016.05.011

Levy, D., Ronemus, M., Yamrom, B., Lee, Y. H., Leotta, A., Kendall, J., et al. (2011). Rare de novo and transmitted copy-number variation in autistic spectrum disorders. Neuron 70, 886-897. doi: 10.1016/j.neuron.2011.05.015

Liang, J., Xu, W., Hsu, Y. T., Yee, A. X., Chen, L., and Sudhof, T. C. (2015). Conditional neuroligin-2 knockout in adult medial prefrontal cortex links chronic changes in synaptic inhibition to cognitive impairments. Mol. Psychiatry 20, 850-859. doi: 10.1038/mp.2015.31

Liu, L., Sun, L., Li, Z. H., Li, H. M., Wei, L. P., Wang, Y. F., et al. (2013). BAIAP2 exhibits association to childhood ADHD especially predominantly inattentive subtype in Chinese Han subjects. Behav. Brain Funct. 9:48. doi: 10.1186/1744-9081-9-48

Lo, S. C., Scearce-Levie, K., and Sheng, M. (2016). Characterization of social behaviors in caspase-3 deficient mice. Sci. Rep. 6:18335. doi: 10.1038/srep18335

Madisen, L., Zwingman, T. A., Sunkin, S. M., Oh, S. W., Zariwala, H. A., Gu, H., et al. (2010). A robust and high-throughput Cre reporting and characterization system for the whole mouse brain. Nat. Neurosci. 13, 133-140. doi: 10.1038/ nn. 2467

Monteiro, P., and Feng, G. (2017). SHANK proteins: roles at the synapse and in autism spectrum disorder. Nat. Rev. Neurosci. 18, 147-157. doi: 10.1038/nrn. 2016.183

Moy, S. S., Nadler, J. J., Perez, A., Barbaro, R. P., Johns, J. M., Magnuson, T. R., et al. (2004). Sociability and preference for social novelty in five inbred strains: an approach to assess autistic-like behavior in mice. Genes Brain Behav. 3, 287-302. doi: 10.1111/j.1601-1848.2004.00076.x
Mundy, P. (2003). Annotation: the neural basis of social impairments in autism: the role of the dorsal medial-frontal cortex and anterior cingulate system. J. Child Psychol. Psychiatry 44, 793-809. doi: 10.1111/1469-7610.00165

Murugan, M., Jang, H. J., Park, M., Miller, E. M., Cox, J., Taliaferro, J. P., et al. (2017). Combined social and spatial coding in a descending projection from the prefrontal cortex. Cell 171, 1663.16-1677.16. doi: 10.1016/j.cell.2017. 11.002

Nelson, S. B., and Valakh, V. (2015). Excitatory/inhibitory balance and circuit homeostasis in autism spectrum disorders. Neuron 87, 684-698. doi: 10.1016/j. neuron.2015.07.033

Park, J., and Moghaddam, B. (2017). Risk of punishment influences discrete and coordinated encoding of reward-guided actions by prefrontal cortex and VTA neurons. Elife 6:e30056. doi: 10.7554/elife.30056

Phillips, M. L., Robinson, H. A., and Pozzo-Miller, L. (2019). Ventral hippocampal projections to the medial prefrontal cortex regulate social memory. Elife 8:e44182. doi: 10.7554/elife.44182

Pierce, K., Haist, F., Sedaghat, F., and Courchesne, E. (2004). The brain response to personally familiar faces in autism: findings of fusiform activity and beyond. Brain 127, 2703-2716. doi: 10.1093/brain/awh289

Pirone, A., Alexander, J. M., Koenig, J. B., Cook-Snyder, D. R., Palnati, M., Wickham, R. J., et al. (2018). Social stimulus causes aberrant activation of the medial prefrontal cortex in a mouse model with autism-like behaviors. Front. Synaptic Neurosci. 10:35. doi: 10.3389/fnsyn.2018.00035

Purcell, S. M., Moran, J. L., Fromer, M., Ruderfer, D., Solovieff, N., Roussos, P., et al. (2014). A polygenic burden of rare disruptive mutations in schizophrenia. Nature 506, 185-190. doi: 10.1038/nature12975

Ribasés, M., Bosch, R., Hervás, A., Ramos-Quiroga, J. A., Sánchez-Mora, C., Bielsa, A., et al. (2009). Case-control study of six genes asymmetrically expressed in the two cerebral hemispheres: association of BAIAP2 with attention-deficit/hyperactivity disorder. Biol. Psychiatry 66, 926-934. doi: 10.1016/j.biopsych.2009.06.024

Riga, D., Matos, M. R., Glas, A., Smit, A. B., Spijker, S., and Van Den Oever, M. C. (2014). Optogenetic dissection of medial prefrontal cortex circuitry. Front. Syst. Neurosci. 8:230. doi: 10.3389/fnsys.2014.00230

Rinaldi, T., Perrodin, C., and Markram, H. (2008). Hyper-connectivity and hyperplasticity in the medial prefrontal cortex in the valproic acid animal model of autism. Front. Neural Circuits 2:4. doi: 10.3389/neuro.04.004.2008

Root, D. H., Melendez, R. I., Zaborszky, L., and Napier, T. C. (2015). The ventral pallidum: subregion-specific functional anatomy and roles in motivated behaviors. Prog. Neurobiol. 130, 29-70. doi: 10.1016/j.pneurobio.2015. 03.005

Rothwell, P. E., Fuccillo, M. V., Maxeiner, S., Hayton, S. J., Gokce, O., Lim, B. K., et al. (2014). Autism-associated neuroligin-3 mutations commonly impair striatal circuits to boost repetitive behaviors. Cell 158, 198-212. doi: 10.1016/j. cell.2014.04.045

Sala, C., and Segal, M. (2014). Dendritic spines: the locus of structural and functional plasticity. Physiol. Rev. 94, 141-188. doi: 10.1152/physrev. 00012.2013

Sala, C., Vicidomini, C., Bigi, I., Mossa, A., and Verpelli, C. (2015). Shank synaptic scaffold proteins: keys to understanding the pathogenesis of autism and other synaptic disorders. J. Neurochem. 135, 849-858. doi: 10.1111/jnc.13232

Sawallisch, C., Berhörster, K., Disanza, A., Mantoani, S., Kintscher, M., Stoenica, L., et al. (2009). The insulin receptor substrate of $53 \mathrm{kDa}$ (IRSp53) limits hippocampal synaptic plasticity. J. Biol. Chem. 284, 9225-9236. doi: 10.1074/jbc.m808425200

Selimbeyoglu, A., Kim, C. K., Inoue, M., Lee, S. Y., Hong, A. S. O., Kauvar, I., et al. (2017). Modulation of prefrontal cortex excitation/inhibition balance rescues social behavior in CNTNAP2-deficient mice. Sci. Transl. Med. 9:eaah6733. doi: 10.1126/scitranslmed.aah6733

Sesack, S. R., Deutch, A. Y., Roth, R. H., and Bunney, B. S. (1989). Topographical organization of the efferent projections of the medial prefrontal cortex in the rat: an anterograde tract-tracing study with Phaseolus vulgaris leucoagglutinin. J. Comp. Neurol. 290, 213-242. doi: 10.1002/cne.902900205

Shalom, D. B. (2009). The medial prefrontal cortex and integration in autism. Neuroscientist 15, 589-598. doi: 10.1177/1073858409336371

Sheng, M., and Hoogenraad, C. C. (2007). The postsynaptic architecture of excitatory synapses: a more quantitative view. Annu. Rev. Biochem. 76, 823-847. doi: 10.1146/annurev.biochem.76.060805.160029 
Sheng, M., and Kim, E. (2011). The postsynaptic organization of synapses. Cold Spring Harb. Perspect. Biol. 3:a005678. doi: 10.1101/cshperspect.a0 05678

Sheng, M., and Sala, C. (2001). PDZ domains and the organization of supramolecular complexes. Annu. Rev. Neurosci. 24, 1-29. doi: 10.1146/annurev.neuro.24.1.1

Silverman, J. L., Yang, M., Lord, C., and Crawley, J. N. (2010). Behavioural phenotyping assays for mouse models of autism. Nat. Rev. Neurosci. 11, 490-502. doi: 10.1038/nrn2851

Testa-Silva, G., Loebel, A., Giugliano, M., De Kock, C. P., Mansvelder, H. D., and Meredith, R. M. (2012). Hyperconnectivity and slow synapses during early development of medial prefrontal cortex in a mouse model for mental retardation and autism. Cereb. Cortex 22, 1333-1342. doi: 10.1093/cercor/bhr224

Toma, C., Hervás, A., Balmaña, N., Vilella, E., Aguilera, F., Cuscó, I., et al. (2011). Association study of six candidate genes asymmetrically expressed in the two cerebral hemispheres suggests the involvement of BAIAP2 in autism. J. Psychiatr. Res. 45, 280-282. doi: 10.1016/j.jpsychires.2010.09.001

Walf, A. A., and Frye, C. A. (2007). The use of the elevated plus maze as an assay of anxiety-related behavior in rodents. Nat. Protoc. 2, 322-328. doi: 10.1038/nprot.2007.44

Wang, X., Ma, S., Mao, M., Li, C., Shen, X., Xu, S., et al. (2019). RNAsequencing and bioinformatics analysis of long noncoding RNAs and mRNAs in the prefrontal cortex of mice following repeated social defeat stress. Biomed. Res. Int. 2019:7505260. doi: 10.1155/2019/ 7505260

Wang, W., Rein, B., Zhang, F., Tan, T., Zhong, P., Qin, L., et al. (2018). Chemogenetic activation of prefrontal cortex rescues synaptic and behavioral deficits in a mouse model of $16 \mathrm{p} 11.2$ deletion syndrome. J. Neurosci. 38, 5939-5948. doi: 10.1523/JNEUROSCI.0149-18.2018

Werling, D. M., and Geschwind, D. H. (2013). Sex differences in autism spectrum disorders. Curr. Opin. Neurol. 26, 146-153. doi: 10.1097/WCO. 0b013e32835ee548

Werling, D. M., Parikshak, N. N., and Geschwind, D. H. (2016). Gene expression in human brain implicates sexually dimorphic pathways in autism spectrum disorders. Nat. Commun. 7:10717. doi: 10.1038/ncomms10717

Yizhar, O., Fenno, L. E., Prigge, M., Schneider, F., Davidson, T. J., O'Shea, D. J., et al. (2011). Neocortical excitation/inhibition balance in information processing and social dysfunction. Nature 477, 171-178. doi: 10.1038/nature 10360

Yoo, T., Cho, H., Park, H., Lee, J., and Kim, E. (2019). Shank3 exons 14-16 deletion in glutamatergic neurons leads to social and repetitive behavioral deficits associated with increased cortical layer $2 / 3$ neuronal excitability. Front. Cell. Neurosci. 13:458. doi: 10.3389/fncel.2019.00458

Conflict of Interest: The authors declare that the research was conducted in the absence of any commercial or financial relationships that could be construed as a potential conflict of interest.

Copyright (C) $2020 \mathrm{Kim}$, Noh, Kim, Yang, Kim and Kim. This is an open-access article distributed under the terms of the Creative Commons Attribution License (CC BY). The use, distribution or reproduction in other forums is permitted, provided the original author(s) and the copyright owner(s) are credited and that the original publication in this journal is cited, in accordance with accepted academic practice. No use, distribution or reproduction is permitted which does not comply with these terms. 